\title{
Is there a genetic basis for Fuchs' heterochromic uveitis? Discordance in monozygotic twins
}

Department of Ophthalmology, University of Manchester N P Jones

Department of Medical Genetics, University of Manchester A P Read

Correspondence to: Mr N P Jones, FRCS, University Department of Ophthalmology, Manchester Royal Eye Hospital, Oxford Road, Manchester M13 9WH. Accepted for publication 30 May 1991

\author{
N P Jones, A P Read
}

\begin{abstract}
One pair, and probably two pairs, of monozygotic twins are reported with discordance for Fuchs' heterochromic uveitis (FHU). Regular Mendelian inheritance of this disease is now proved to be impossible. The heritability of FHU is low and may be zero. The possibility of any genetic predisposition to the disease and its association with 'simple' heterochromia are discussed.
\end{abstract}

Fuchs' heterochromic uveitis (FHU) is a chronic, indolent uveitis of unknown aetiology first described comprehensively by Ernst Fuchs in 1906.' The occasional concurrence of FHU in more than one member of the same family has been reported ${ }^{2-5}$ and the possibility of a genetic aetiology, usually described as an autosomal dominant trait with low penetrance, has been discussed on several occasions. In 1955, Franceschetti, ${ }^{6}$ having reported a large series of 62 patients with FHU and established the modern criteria for diagnosis, concluded that 'If one day we have the good fortune to find identical twins with Fuchs' syndrome, we hope it will then be easier to answer the difficult question of the role of a genetic factor in complicated heterochromia'. Almost immediately, FHU coexisting in a pair of monozygotic twins was described, ${ }^{7}$ and the possibility of a genetic factor was further strengthened. Family studies on a cohort of 103 patients with FHU are reported here, including case reports of discordance of FHU in monozygotic twins. The implications of these findings on a genetic theory for FHU are discussed.

\section{Patients and methods}

From 1987 all new and old patients attending the outpatient department at Manchester Royal Eye Hospital with a definite or suggested diagnosis of FHU were referred to one of us (NPJ). Of these, 103 patients were considered to fulfil the diagnostic criteria for FHU. As part of a comprehensive history and examination these patients were questioned on their family history and a family tree was constructed. Any history of possible heterochromia or inflammatory eye disease was noted. Where possible allegedly affected family members were examined. DNA analysis on a pair of monozygotic twins was performed.

\section{Results}

In 13 cases the family history was incomplete or unknown due to lack of knowledge on the part of the patient (two being adopted). Of the remaining 90 patients (who had a total of 601 first degree relatives) $84(93.3 \%)$ had no family history of heterochromia or ocular disease. Six patients $(6.7 \%)$, however, each thought that one other family member had heterochromia. For geographical and other reasons it was possible to examine only two of these six suggested cases. In both instances there was unilateral sector hyperpigmentation, no sign of past or present intraocular inflammation, and otherwise normal ocular examination. This cohort of 103 patients included two who had a monozygotic twin, but no dizygotic twins. Both are reported below.

\section{Case reports}

CASE 1

The patient, a 51-year-old woman, presented with a history of gradual loss of vision on the left side. She was aware of heterochromia affecting the left side which had been present since birth. This eye was known to be amblyopic but further visual loss had occurred.

On examination of the left eye there were numerous stellate keratic precipitates scattered evenly over the whole posterior surface of the cornea, with fine interconnecting fibrillary deposits. There were few cells in the anterior chamber and barely detectable flare. The right iris had a normal architecture and was light brown'(Fig 1). The left iris was macroscopically blue, the anterior border layer pigment had entirely disappeared, and this layer was grossly atrophic (Fig 2). The iris stroma was also markedly atrophic with obvious thinning and some visibility of pigment epithelium from the anterior aspect. The iris pigment epithelium was clearly abnormal and there were large scattered transillumination defects, mainly peripheral but also involving the pigment ruff. The pupil on this side was slightly irregular, but there were no posterior synechiae. A posterior subcapsular cataract was present, and vitreous cellular activity and condensations were visible. There were no fundal lesions. The diagnosis of FHU was made.

The patient was one of triplets. There was no history of maternal illness in pregnancy, and the patient was delivered vaginally at term without complications. One further child, a girl, was delivered without mishap but a third female was stillborn and small.

The surviving twin was examined. The eyes were completely normal. The irides were a very similar colour to the normal right iris of the patient; stromal architecture and pigmentation were symmetrical and normal. There was no evidence of past or present intraocular inflammation and the lenses were clear. There was therefore no evidence of FHU (Figs 3 and 4). 


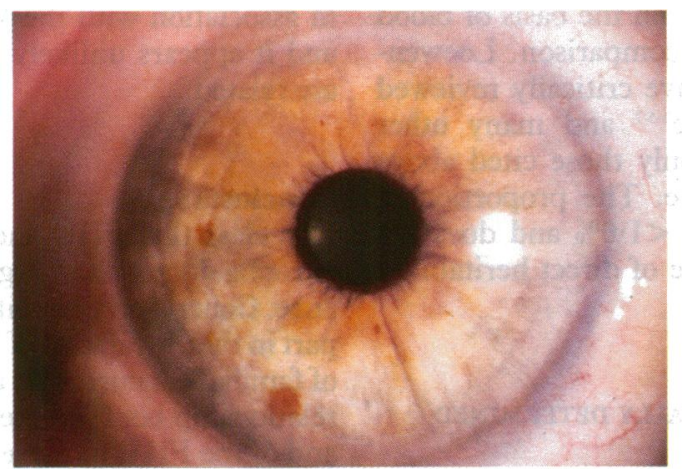

Figure 1 Case 1. The twin with Fuchs' heterochromic uveitis, normal right eye.

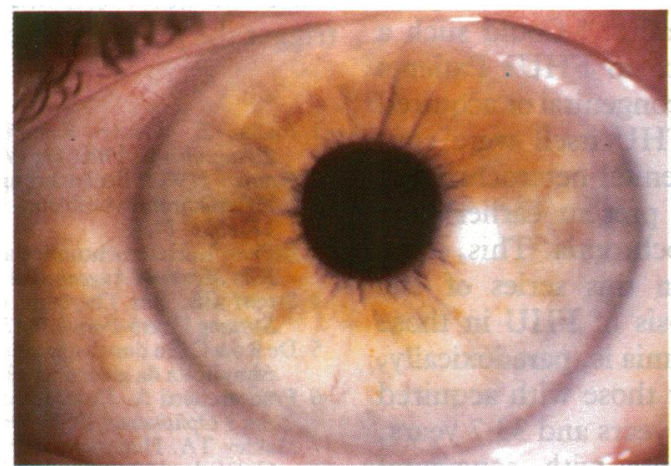

Figure 3 Case 1. The unaffected twin, right eye.

The twins were facially very similar even at 51 years of age, and in fact the patient's heterochromia had been a useful distinguishing feature in childhood. DNA analysis was performed by means of the minisatellite probe 33.6 , which showed that each twin had 25 clearly visible bands, which were in identical positions.

CASE 2

This female patient presented at the age of 69 with a history of floaters. She was aware of her profound heterochromia, which had been present since birth. On examination she had clear evidence of right-sided heterochromic uveitis, with widespread stellate keratic precipitates and typical iris atrophy with hypochromia. There was incipient band keratopathy. The affected iris was blue, the unaffected one being light brown. The lens was clear but there was cellular activity in the anterior vitreous.

The diagnosis of FHU was made. The patient had no family history of heterochromia and was one of twins. The maternal pregnancy and delivery had been uneventful. The twin had unfortunately died recently at the age of 72 , and a planned ocular examination and DNA analysis had not been possible. Anecdotally the surviving twin was convinced both of their monozygosity and their discordance for heterochromia. The heterochromia had apparently been the only distinguishing feature in childhood.

\section{Discussion}

The issue of a possible genetic basis for FHU has been raised on several occasions in the past. Evidence for this might be sought from twin studies, from evidence that FHU tends to be

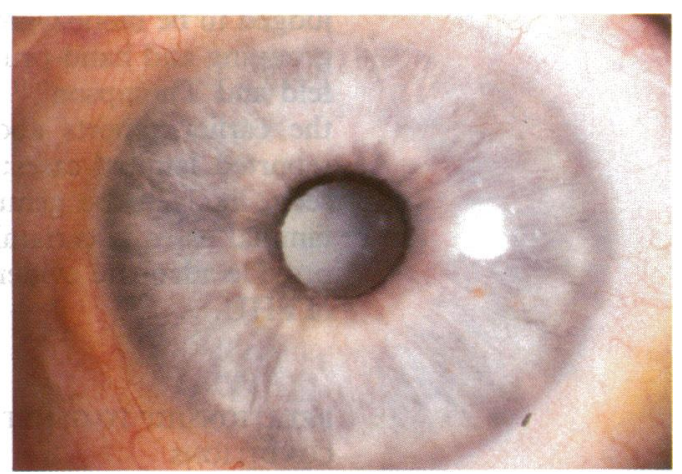

Figure 2 Case 1. The twin with Fuchs' heterochromic uveitis, affected left eye.

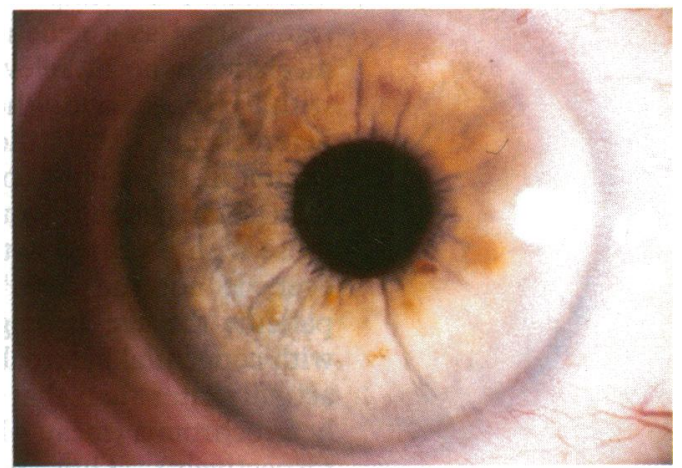

Figure 4 Case 1. The unaffected twin, left eye.

familial, or from evidence of a relationship to more clearly defined genetic conditions.

\section{TWIN STUDIES}

Makley ${ }^{7}$ found a pair of presumed monozygotic twins in 1956 who were concordant for FHU. The possibility of a non-genetic aetiology still existed of course, as the twins had occupied the same uterus simultaneously. However, our finding of one, and probably two, pairs of discordant monozygotic twins now formally disproves any wholly genetic aetiology for FHU. The twins in case 1 shared all 25 bands seen with DNA fingerprinting. The chance of dizygotic twins sharing one band is about $0 \cdot 6,{ }^{8}$ and the chance of sharing all 25 is $(0.6)^{25}$ or $3 \times 10^{-6}$. Thus they are monozygotic, and they are certainly discordant for FHU. Probably the twins in case 2 were also monozygotic, since the heterochromia in one of them was reportedly the only distinguishing feature in childhood.

\section{EVIDENCE FOR FAMILIAL TRANSMISSION}

Some authors ${ }^{9}{ }^{10}$ have described FHU as a dominant condition with low penetrance, but the reported series show that in the vast majority of instances it is not familial. In the literature to date approximately 1800 cases of FHU have been reported. ${ }^{11-16}$ Familial cases have been published in a few instances, but it should be noted that selective reporting of familial transmission ${ }^{3-5}$ may overestimate the possibility of heritability. The reports of familial transmission include: two sisters ${ }^{2}$; a mother and daughter ${ }^{3}$; an uncle and nephew ${ }^{+}$; two sisters ${ }^{5}$; and five further families. ${ }^{1317}$ In 1956 Makley $^{7}$ reported the coexistence of FHU in a pair of twins, who were 
judged to be monozygotic on the basis of blood grouping and hand-print comparison. Loewenfeld and Thompson ${ }^{112}$ have critically reviewed the earlier reports above ${ }^{2-57}$ and many other reported familial cases; only those cited above seem likely to be genuine. The proportion of familial cases is certainly $<1.0 \%$ and does not provide adequate evidence of direct heritability of FHU.

\section{RELATIONSHIP TO GENETICALLY DETERMINED CONDITIONS}

There is a possibility that both sector hyperpigmentation of the iris, and heterochromia without inflammation ('simple' heterochromia) may be transmitted as a genetic trait. ${ }^{18}{ }^{19}$ Could such a mechanism be of relevance to FHU? Patients with FHU can have either congenital or acquired heterochromia. ${ }^{616}$ If the FHU itself were congenital in those with congenital heterochromia, then such patients would present earlier than those with acquired heterochromia. This, however, is not the case. ${ }^{16}$ In this series of 103 patients the age at diagnosis of FHU in those with congenital heterochromia is, paradoxically, actually later than that for those with acquired heterochromia (mean 41.4 years and 33.7 years, respectively). Thus patients with congenital heterochromia must have a latent period without inflammation before FHU develops. At this time, therefore, they have 'simple' heterochromia. It should be considered a possibility that simple heterochromia is transmitted as a genetic trait, and that FHU arises as a complication in some (probably most) of these.

Heterochromia can occur as a dominant condition, either as part of the Waardenburg syndrome or, more questionably, in isolation. ${ }^{19}$ In the Waardenburg syndrome the underlying cause lies in the neural crest. ${ }^{20}$ In our series there was anecdotal evidence of heterochromia in six out of 601 first degree relatives. In the two relatives we were able to examine there was unilateral sector hyperpigmentation. The heterochromia seen in Waardenburg syndrome is also of ten unilateral and segmental (Newton V, personal communication). However the underlying pathology must be quite different because FHU is not a complication of Waardenburg syndrome. ${ }^{12}$ True FHU has not been described in association with the Waardenburg syndrome and it appears unlikely that the two conditions are related.

\section{Conclusions}

It is clear that FHU and its antecedent heterochromia do not show regular Mendelian inheritance. Genetic predisposition does not play a large part in the overall risk of FHU. The very low rate of familial concurrence, and the lack of temporal relationship between the onset of heterochromia and of the FHU in those with congenital heterochromia, suggest that at least two rare events are required, one (which may be intrauterine) to cause the heterochromia and a second event to trigger the progression to FHU.

1 Fuchs E. Ueber Komplicationen der Heterochromie. Z Augenheilkd 1906; 15: 191-212.

$2 \mathrm{Kranz}$ HW. Beobachtungen und Bemerkungen zum Heterochromie-problem. Graefes Arch Ophthalmol 1926; 117: 554-74.

3 Becker J. Heterochromieglaukom bei Mutter und Tochter. Klin Monatsbl Augenheilkd 1927; 78: 707.

4 Streiff EB. Sur l'hérédité de l'hététochromie. Arch Klaus Stiftung Vererb-Forsch 1947; 22: 256-60.

5 De Rosa C. Su due casi familiari di ciclite etrocromica di Fuch complicata da glaucoma. Arch Ottalmol 1959; 63: 437-9.

6 Franceschetti A. Heterochromic cyclitis (Fuchs' syndrome) Am $\mathcal{F}$ Ophthalmol 1955; 39: 50-8.

7 Makley TA. Heterochromic cyclitis in identical twins. $A m \mathcal{F}$ Ophthalmol 1956; 41: 768-72.

8 Jeffreys AJ, Wilson V, Thein SL. Individual-specific fingerprints of human DNA. Nature 1985; 316: 76-9.

9 Bistis J. La paralysie du sympathique dans l'étiologie de l'hétérochromie. Arch Ophtalmol (Paris) 1912; 32: 578.

10 François J. Fuchs' heterochromia. Ann Ocultist (Paris) 1954; 187: 255 .

11 Loewenfeld IE, Thompson S. Fuchs's heterochromic cyclitis. A critical review of the literature I. Clinical characteristics of he syndrome. Surv Ophthalmol 1973; 17: 394-457.

12 Loewenfeld IE, Thompson S. Fuchs's heterochromic cyclitis. A critical review of the literature II. Etiology and mechanisms. Surv Ophthalmol 1973; 18: 2-61.

13 Liesegang TJ. Clinical features and prognosis in Fuchs' uveitis syndrome. Arch Ophthalmol 1982;100: 1622-6.

14 Jain IS, Gupta A, Gangwar DN, Dhir SP. Fuchs' heterochromic cyclitis: Some observations on clinical picture and on cataract surgery. Ann Ophthalmol 1983; 15:640-2.

15 Tabbutt BR, Tessler HH, Williams D. Fuchs' heterochromic iridocyclitis in blacks. Arch Ophthalmol 1988; 106: 1688-90.

16 Jones NP. Fuchs' heterochromic uveitis: A reappraisal of the clinical spectrum. Eye 1991; accepted for publication.

17 Saari M, Vuorre I, Tiilikainen A, Algvere P. Genetic back ground of Fuchs' heterochromic cyclitis. Can $\mathcal{f}$ Ophthalmol 1978; 13: $240-6$.

18 Waardenburg PJ, Franceschetti A, Klein D. Genetics and phthalmology. Oxford: Blackwell, 1961.

19 McKusick VA. Mendelian inheritance in man. 9th ed. Entry 14250: Heterochromia iridis. Baltimore: Johns Hopkins University Press, 1990

20 Foy C, Newton VE, Wellesley D, Harris R, Read AP. Localisation of the gene for Waardenburg syndrome type I to 2q37 and possible homology to the Splotch mouse. Am 7 Hum Genet 1990; 46: 1017-23. 